\title{
Domino ring-opening-ring-closing enyne metathesis vs enyne metathesis of norbornene derivatives with alkynyl side chains. Construction of condensed polycarbocycles
}

\author{
Ritabrata Datta and Subrata Ghosh*
}

\author{
Full Research Paper \\ Address: \\ School of Chemical Sciences, Indian Association for the Cultivation of \\ Science, Jadavpur, Kolkata 700 032, India \\ Email: \\ Subrata Ghosh* - ocsg@iacs.res.in \\ * Corresponding author \\ Keywords: \\ Diels-Alder reaction; domino process; enyne metathesis; natural \\ products; polycarbocycles
}

Open Access

\author{
Beilstein J. Org. Chem. 2018, 14, 2708-2714 \\ doi:10.3762/bjoc. 14.248 \\ Received: 12 August 2018 \\ Accepted: 10 October 2018 \\ Published: 25 October 2018 \\ This article is part of the thematic issue "Progress in metathesis \\ chemistry III". \\ Guest Editor: K. Grela \\ (c) 2018 Datta and Ghosh; licensee Beilstein-Institut. \\ License and terms: see end of document.
}

\begin{abstract}
The metathesis of norbornene derivatives with alkynyl side-chain with Grubbs' ruthenium alkylidine as catalyst has been investigated with the objective of constructing condensed polycyclic structures. This investigation demonstrated that the generally observed domino reaction course involving a ring-opening metathesis of the norbornene unit and a ring-closing enyne metathesis is influenced to a great extent by the nature of the functional group and the substrate structure and may follow a different reaction course than what is usually observed. In cases where ROM-RCEYM occurred, the resulting 1,3-diene reacts in situ with the dienophile to provide condensed tetracyclic systems.
\end{abstract}

\section{Introduction}

The metathesis of norbornene derivatives having an alkene sidechain on the norbornene nucleus with Grubbs' ruthenium catalysts has been extensively investigated. Generally the reaction proceeds through a domino process involving a ring opening of the norbornene nucleus and ring closing with the alkene side chains to produce ring rearrangement products (path 1, Scheme 1) [1-4]. This protocol has been employed by several groups [5-22] as well as by our group [23-33] for the synthesis of a variety of complex ring systems such as condensed, bridged and spirocycles difficult to obtain otherwise. On the contrary, the domino process involving a ring-opening metathesis (ROM) followed by a ring-closing enyne metathesis (RCEYM) [34-37] of norbornene derivatives with a suitably located alkynyl side-chain on the nucleus (path 2, Scheme 1) to form carbocycles has been less explored. The greatest advantage of this protocol lies in its potential in increasing the molecular complexity through Diels-Alder reaction of the resulting ring system. Domino metathesis of oxa- and aza-norbornenes 
with alkyne side chains [38-40] as well as norbornene derivatives having ether linked alkynes [41,42] in combination with Diels-Alder reaction of the resulting 1,3-dienes have been investigated to construct polycycles with heteroatoms. In spite of the great potential little attention has been paid [43] for exploring its application in the synthesis of complex carbocyclic ring systems, backbones of innumerable natural products.

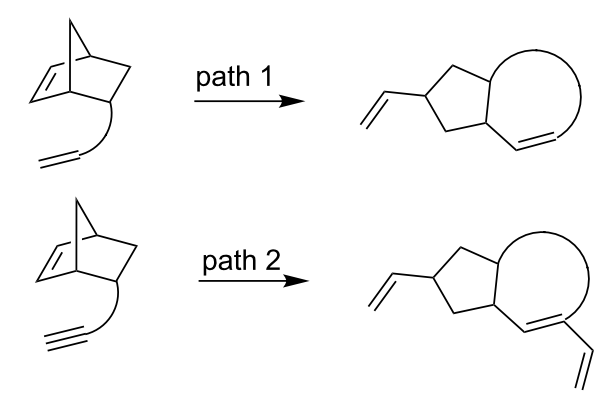

Scheme 1: Metathesis of norbornene derivatives.

We undertook a program for the synthesis of condensed polycarbocyclic scaffolds using a metathesis of norbornene derivatives with suitably located alkynyl side-chains as the key step. The structurally unique sesterterpenes retigeranic acid A (1a) and retigeranic acid B (1b, Figure 1) are representative examples of such complex polycyclic structures [44-47]. We speculated that domino ROM-RCEYM of the norbornene derivative 2 would provide the tricyclic 1,3-diene 3 which on Diels-Alder reaction with a dienophile would enable access to condensed polycyclic structures 4 (Scheme 2). Thus an appropriately chosen norbornene derivative and a dienophile may provide the $\mathrm{B} / \mathrm{C} / \mathrm{D} / \mathrm{E}$ ring system of retigeranic acids. Herein we describe the results of metathesis of norbornene derivatives 2 with alkynyl side-chains.

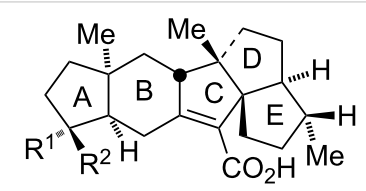

$$
\begin{aligned}
1 \text { a, } R^{1} & =\text { isopropyl, } R^{2}=H \\
\text { b, } R^{1} & =H, R^{2}=\text { isopropyl }
\end{aligned}
$$

Figure 1: Structures of retigeranic acids $A(\mathbf{1 a})$ and $B(\mathbf{1 b})$.

\section{Results and Discussion}

Initially Grubbs' 1st generation catalyst (G-I) was used for metathesis of norbornene derivatives 2 . In case G-I failed to accomplish metathesis in the desired direction, 2nd generation catalyst (G-II) was used. The norbornene derivative 7a was first chosen for investigating ROM-RCEYM. Compound 7a was

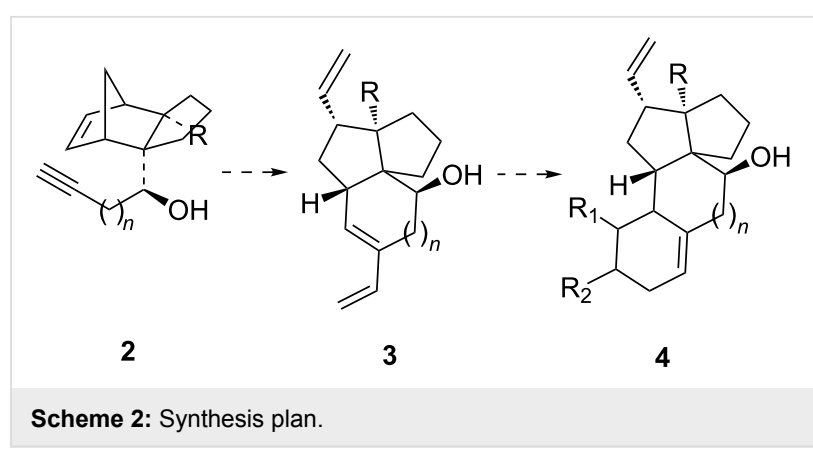

prepared in the following way (Scheme 3). Reaction of the known lactol 5 [33] with propargyl magnesium bromide afforded the diol 6 in 88\% yield (For detailed experimental procedures and characterization data see Supporting Information File 1). The stereochemical orientation of the secondary hydroxy group was determined through X-ray crystal structure of a compound derived from it in a subsequent step. The primary hydroxy group in the diol $\mathbf{6}$ was then selectively protected to provide the silyl ether $7 \mathbf{a}$ in $92 \%$ yield. Two different paths can be invoked for metathesis of compound 7a. Metathesis initiation may occur by attack of the ruthenium alkylidene at the alkyne unit to produce the more substituted vinyl alkylidine intermediate 8a which may undergo concomitant ROM-RCM with the norbornene nucleus to provide the triene 9a (path 1).

Alternatively the metathesis initiation may occur initially at the norbornene double bond to provide the ring-opened ruthenium alkylidine intermediate $\mathbf{1 0}$ (path 2). The latter then undergoes RCEYM to provide the tricycle 9a. With this background a solution of the compound 7a in toluene under ethylene atmosphere was heated at $65^{\circ} \mathrm{C}$ with Grubbs 1 st generation catalyst (G-I). Compound 7a was found to be inert even after a prolonged reaction time. However, with G-II as the catalyst the metathesis went smoothly. Without isolation, the metathesis product was treated in situ with dimethyl acetylenedicarboxylate (DMAD). In case the Diels-Alder reaction would take place through the triene 9a the tetracyclic structure 12a would be formed. However, ${ }^{13} \mathrm{C}$ NMR spectra of the product revealed the presence of eight methylene carbon signals at $\delta 28.6,28.9,30.9$, $33.5,36.7,41.1,45.7$ and 68.8 , one more aliphatic methylene unit than what the structure 12a requires (see Supporting Information File 1). This indicates that the metathesis product is not 9a. The structure of the metathesis product was finally settled by X-ray crystal structure (Figure 2) [48] (see Supporting Information File 2) of the 3,5-dinitrobenzoate derivative 13, mp $171-172{ }^{\circ} \mathrm{C}$, prepared in two steps $(51 \%)$ from the metathesis product on reaction with 3,5-dinitrobenzoyl chloride (DNBC) followed by acid-induced desilylation. Thus compound $\mathbf{7 b}$ on metathesis produced exclusively triene $\mathbf{1 1}$ and accordingly the structure of the Diels-Alder adduct is $\mathbf{1 4}$. The for- 

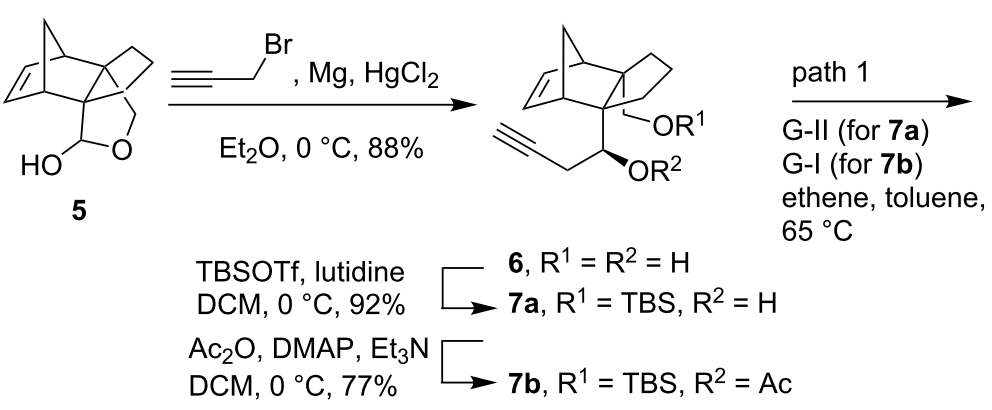
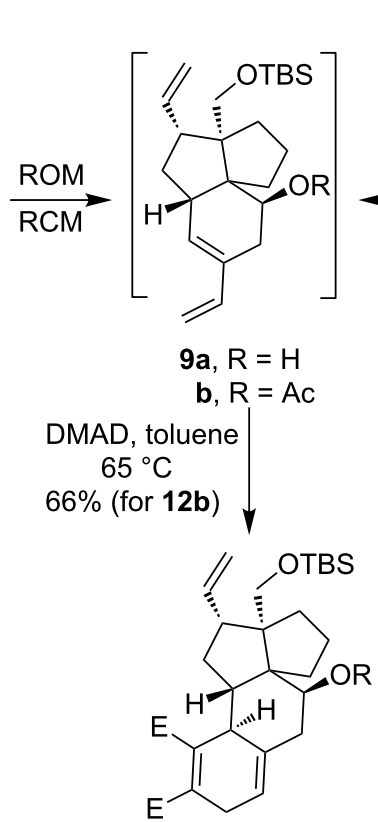

12a, $\mathrm{R}=\mathrm{H}$

b, $R=A c \quad E=$ COOMe

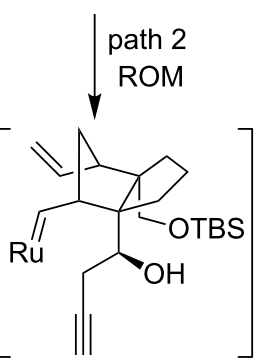

10

$$
\text { (i) 3,5-DNBC, DMAP }
$$

$\mathrm{Et}_{3} \mathrm{~N}, \mathrm{DCM}, \mathrm{rt}$

(ii) $6 \mathrm{~N} \mathrm{HCl}, \mathrm{THF} / \mathrm{H}_{2} \mathrm{O}$

$51 \%$ (in two steps)

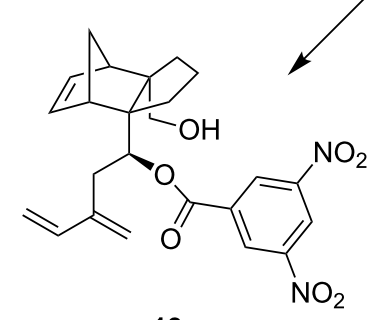

13

DNBC = dinitrobenzoyl chloride

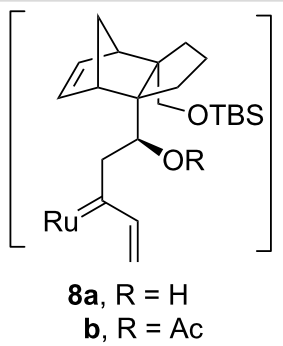

CM with ethene<smiles>C=CC(=C)CC(O)C12CCC(CC1)C1C=CC12O[Sb]</smiles>

11

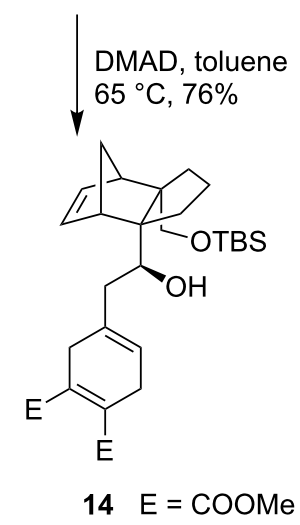

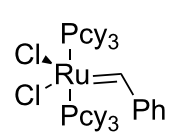

G-I<smiles>CN1CCN(S(C)(=O)=O)C1[R]([18OH])(Cl)(Cl)/C=C\c1ccccc1</smiles>

G-II

Scheme 3: Metathesis of norbornene derivatives $7 a$ and $7 b$.

mation of triene 11 could be attributed to cross metathesis of the ruthenium alkylidene 8a with ethylene. No product arising out of ROM of norbornene derivative 7a was formed. It is worth mentioning that Spandl et al. [43] reported the metathesis of norbornene derivatives with an alkynyl side chain affording the major product arising from domino ROM-RCEYM while the enyne metathesis product was observed only in very low yield.

In order to realize our objective and to find out if the free hydroxy group has any influence on the outcome of the metathesis, the hydroxy group in compound $7 \mathbf{a}$ was protected to provide the acetate derivative $\mathbf{7 b}$. The metathesis of compound 7b with G-I as the catalyst proceeded smoothly and the resulting product without isolation was allowed to react with DMAD to produce the tetracycle $\mathbf{1 2 b}$ in overall $66 \%$ yield. The structure of compound 12b was established through analysis of its NMR spectra. Isolation of $\mathbf{1 2 b}$ dictated that metathesis of $\mathbf{7 b}$ proceeded through the formation of the triene $\mathbf{9 b}$. Stereochemical assignment to the adduct follows from addition of the dienophile from the least hindered face (opposite to $\mathrm{CH}_{2} \mathrm{OTBS}$ group) of the diene. Thus unlike metathesis of $7 \mathbf{a}$, metathesis of its acetate analogue $\mathbf{7 b}$ occurred through a domino ROM-RCEYM process. Addition of the Ru-carbene $\mathbf{1 0}$ arising from ring opening of norbornene unit in $\mathbf{7 b}$ could add to the 


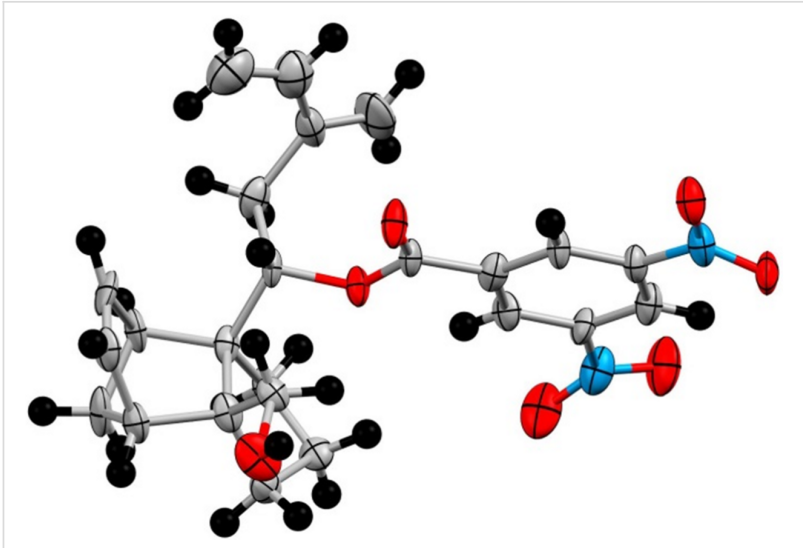

Figure 2: ORTEP of compound 13 (ellipsoids at 30\% probability).

acetylenic unit of another molecule of $7 \mathbf{b}$ leading to copolymerization. However, this process generally does not take place under such low molar concentration of the substrate [38-43] We also did not isolate any copolymerization product. This may be attributed to the much faster rate of addition of the Ru-carbene $\mathbf{1 0}$ to the yne unit intramolecularly resulting in ring closure rather than intermolecular addition to an acetylenic unit of another molecule of $\mathbf{7 b}$. It may be noted that changing the functional group from hydroxy to acetate the metathesis followed a different reaction course.

In order to construct a polycyclic structure analogous to the $\mathrm{B} / \mathrm{C} / \mathrm{D} / \mathrm{E}$ ring of retigeranic acids, the norbornene derivative $\mathbf{1 6}$ was chosen. Addition of lithium (trimethylsilyl)acetylide to the lactol 5 followed by desilylation by using methanolic $\mathrm{K}_{2} \mathrm{CO}_{3}$ afforded diol 15 (Scheme 4). The primary hydroxy group in compound $\mathbf{1 5}$ was selectively protected to produce the silyl ether $\mathbf{1 6}$ in $95 \%$ yield. The attempted metathesis of compound 16 with G-I or G-II catalyst under the conditions used for the metathesis of $7 \mathbf{a}$ led to a complete recovery of $\mathbf{1 6}$. Since metathesis of the acetate derivative $\mathbf{7 b}$ proceeded smoothly in the desired direction, we chose to use the acetate $\mathbf{1 7}$ for metathesis. The acetate $\mathbf{1 7}$ also remained inert when subjected to metathesis conditions with G-I as well as with G-II. Neither ring opening of the norbornene nucleus nor cross metathesis of the alkyne with ethylene did occur. To have an understanding about the inertness of $\mathbf{1 7}$ towards metathesis we decided to prepare the ring-opened product 18 using an alternative path. The double bond in the norbornene nucleus in compound $\mathbf{1 7}$ was cleaved in the traditional way by treatment with $\mathrm{OsO}_{4} / \mathrm{NaIO}_{4}$ and the resulting dialdehyde on Wittig reaction provided the diene $\mathbf{1 8}$ in $66 \%$ yield in two steps. Amazingly when compound 18 was treated with G-I or G-II as catalyst, the metathesis was found to take place. After disappearance of the starting material (TLC), the reaction mixture was allowed to react with DMAD. The product obtained in $76 \%$ yield was assigned the structure 20 based on spectral data. Isolation of $\mathbf{2 0}$ indicates that metathesis of 18 proceeded through RCEYM to produce the triene 19 . The latter then after in situ Diels-Alder reaction with DMAD delivered the product $\mathbf{2 0}$. The tetracyclic compound $\mathbf{2 0}$ represents the $\mathrm{B} / \mathrm{C} / \mathrm{D} / \mathrm{E}$ tetracyclic core structure of retigeranic acids.

Based on the above observations a mechanistic rationale regarding the metathesis of norbornene derivatives with an alkynyl side chain may be postulated (Figure 3). Possibly the
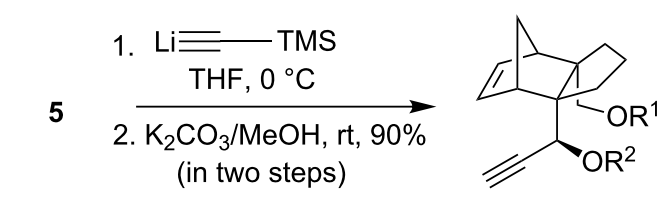

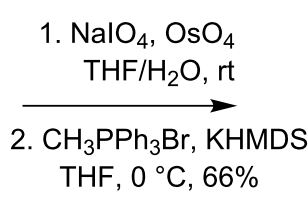

(in two steps)

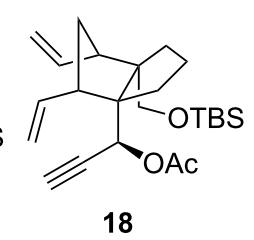

18

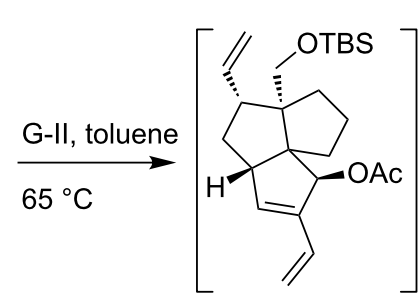

19
15, $R^{1}=R^{2}=H$

16, $R^{1}=$ OTBS, $R^{2}=H$

17, $R^{1}=$ OTS, $R^{2}=A C$

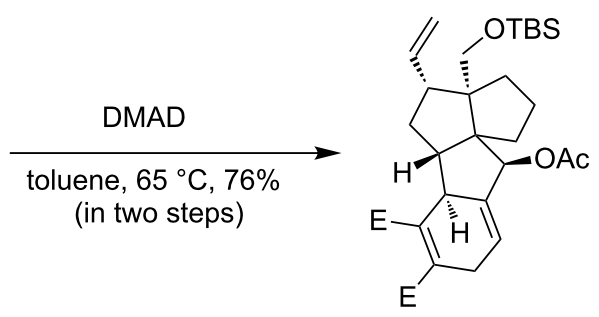

20, $\mathrm{E}=\mathrm{COOMe}$ 
metathesis is initiated at the acetylenic unit to form the ruthenium alkylidine such as $\mathbf{8}$. In case of $\mathbf{8 a}$ the ruthenium alkylidine is stabilized by formation of the chelate $21(\mathrm{R}=\mathrm{H})$ which prohibits intramolecular addition of the ruthenium alkylidine to form ruthena cyclobutane 22. The alkylidine $\mathbf{2 1}$ then undergoes cross metathesis with ethylene to form the product 11 . The ruthenium alkylidine $\mathbf{8 b}$ possibly fails to form chelate $\mathbf{2 1}(\mathrm{R}=\mathrm{Ac})$ due to the electron deficient nature of the OAc group. It forms intramolecularly the ruthena cyclobutane $\mathbf{2 2}$ which undergoes ring opening to give rise to the triene $\mathbf{9 b}$. That the metathesis does not proceed through path 2 (Scheme 3 ) involving ROM-RCM is indicated by failure of the norbornene derivative 17 to undergo ROM. Steric shielding of the acetylenic unit in $\mathbf{1 7}$ inhibits metathesis initiation at the acetylenic unit. The norbornene derivative $\mathbf{1 7}$ just remains inert under metathesis conditions. Thus metathesis in these examples proceeds through path 1 (Scheme 3).

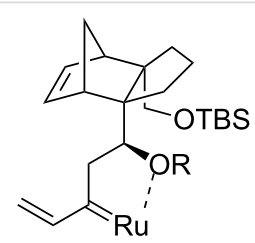

21

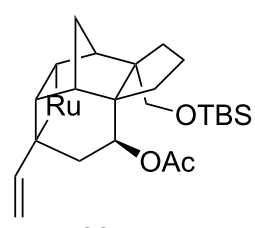

22
Figure 3: Probable metathesis intermediates.

\section{Conclusion}

In conclusion we have developed a protocol for the synthesis of condensed polycycles from metathesis of norbornene derivatives with alkynyl side-chain. This investigation demonstrated that domino metathesis of norbornene derivatives with alkynyl side-chain requires metathesis initiation at the acetylene unit. Further, the nature of functional groups as well as the substrate structure play a significant role in determining the metathesis reaction course.

\section{Experimental}

General experimental methods are similar as described in [49]

Synthesis of triene 11. A solution of the silyl ether 7a (120 mg, $0.35 \mathrm{mmol})$ in degassed toluene $(7 \mathrm{~mL})$ with Grubbs' catalyst G-II (30 mg, $0.035 \mathrm{mmol}$ ) was heated at $65{ }^{\circ} \mathrm{C}$ for $6 \mathrm{~h}$ under a positive pressure of ethylene atmosphere. After completion (TLC) of the reaction toluene was removed under vacuo. The residual mass was purified by column chromatography (7\% EA/PE) to afford diene 11 (89 $\mathrm{mg}, 69 \%$ ) as an oil; ${ }^{1} \mathrm{H}$ NMR $(500 \mathrm{MHz}) \delta 6.42(\mathrm{dd}, J=11,17.5 \mathrm{~Hz}, 1 \mathrm{H}), 6.12(\mathrm{~s}$, $2 \mathrm{H}), 5.28(\mathrm{~d}, J=17.5 \mathrm{~Hz}, 1 \mathrm{H}), 5.15(\mathrm{~d}, J=29 \mathrm{~Hz}, 2 \mathrm{H}), 5.04(\mathrm{~d}$, $J=11 \mathrm{~Hz}, 1 \mathrm{H}), 3.98(\mathrm{~s}, 1 \mathrm{H}), 3.63(\mathrm{~d}, J=10 \mathrm{~Hz}, 1 \mathrm{H}), 3.56(\mathrm{~s}$, $2 \mathrm{H}), 2.53(\mathrm{~s}, 1 \mathrm{H}), 2.45-2.42(\mathrm{~m}, 1 \mathrm{H}), 2.36-2.22(\mathrm{~m}, 3 \mathrm{H})$,
1.95-1.92 (m, 1H), 1.82-1.74 (m, 3H), 1.47-1.38 (m, 2H), $1.33-1.28(\mathrm{~m}, 1 \mathrm{H}), 0.89(\mathrm{~s}, 9 \mathrm{H}), 0.07(\mathrm{~s}, 6 \mathrm{H}) ;{ }^{13} \mathrm{C} \mathrm{NMR}$ $(125 \mathrm{MHz}) \delta 144.3,139.8,136.4,136.1,117.0,113.1,71.9$, $68.6,63.4,61.2,52.2,52.0,45.8,36.8,36.0,33.8,28.8$, 26.0 ( $\times 3), 18.4,-5.4,-5.6$; HRMS-ESI $m / z:[\mathrm{M}+\mathrm{Na}]^{+}$calcd for $\mathrm{C}_{23} \mathrm{H}_{38} \mathrm{O}_{2} \mathrm{SiNa}$ 397.2539; found, 397.2537.

Diels-Alder reaction of diene 11. Synthesis of adduct 14 . A mixture of the diene 11 (40 mg, $0.11 \mathrm{mmol}$ ) and dimethyl acetylenedicarboxylate $(0.02 \mathrm{~mL}, 0.16 \mathrm{mmol})$ in toluene $(5 \mathrm{~mL})$ was heated at $65{ }^{\circ} \mathrm{C}$ for $2 \mathrm{~h}$. The solvent was removed under reduced pressure and was purified by column chromatography $(12 \% \mathrm{EA} / \mathrm{PE})$ to afford the Diels-Alder adduct 14 (42 $\mathrm{mg}$, $76 \%$ ) as an oil; ${ }^{1} \mathrm{H}$ NMR (500 MHz) $\delta 6.12-6.11(\mathrm{~m}, 2 \mathrm{H}), 5.52$ $(\mathrm{s}, 1 \mathrm{H}), 4.26(\mathrm{~s}, 1 \mathrm{H}), 3.89-3.88(\mathrm{~m}, 1 \mathrm{H}), 3.78(\mathrm{~s}, 3 \mathrm{H}), 3.76(\mathrm{~s}$, $3 \mathrm{H}), 3.60-3.52(\mathrm{~m}, 3 \mathrm{H}), 3.05-2.97(\mathrm{~m}, 3 \mathrm{H}), 2.45(\mathrm{~s}, 1 \mathrm{H}), 2.32$ (s, 1H), 2.18-2.17 (m, 3H), 1.93-1.89 (m, 1H), 1.83-1.78 (m, 2H), 1.75-1.68 (m, 2H), 1.48-1.41 (m, 1H), 1.39-1.33 (m, 2H), $0.88(\mathrm{~s}, 9 \mathrm{H}), 0.08(\mathrm{~s}, 6 \mathrm{H}) ;{ }^{13} \mathrm{C} \mathrm{NMR}(75 \mathrm{MHz}) \delta 169.0,168.7$, 136.4, 135.8, 133.6, 132.4, 132.2, 117.9, 72.0, 68.8, 63.1, 61.2, $52.3(\times 2), 52.1(\times 2), 45.7,41.1,36.8,33.6,30.9,28.9,28.6$, $26.0(\times 3), 18.4,-5.4,-5.6$; IR: 2952, $1728,1471 \mathrm{~cm}^{-1}$; HRMS-ESI $m / z$ : $[\mathrm{M}+\mathrm{Na}]^{+}$calcd for $\mathrm{C}_{29} \mathrm{H}_{44} \mathrm{O}_{6} \mathrm{SiNa} 539.2805$; found, 539.2802.

Synthesis of tetracycle $12 \mathrm{~b}$. A solution of the norbornene derivative $7 \mathbf{b}$ (70 $\mathrm{mg}, 0.18 \mathrm{mmol})$ in degassed toluene $(6 \mathrm{~mL})$ was heated with Grubbs' catalyst G-I (15 mg, $0.018 \mathrm{mmol})$ under ethylene atmosphere at $65^{\circ} \mathrm{C}$ for $12 \mathrm{~h}$. After completion (TLC) of the metathesis reaction, dimethyl acetylenedicarboxylate $(0.04 \mathrm{~mL}, 0.27 \mathrm{mmol})$ was added to the reaction mixture. The reaction mixture was then heated for $12 \mathrm{~h}$ till the Diels-Alder reaction of the diene $9 \mathbf{b}$ generated in situ was complete. The solvent was removed under vacuo and the product was purified by column chromatography $(15 \% \mathrm{EA} / \mathrm{PE})$ to afford the tetracycle 12b (66 mg, 66\%) as a colorless oil; ${ }^{1} \mathrm{H}$ NMR $(300 \mathrm{MHz})$ $\delta 5.99-5.87(\mathrm{~m}, 1 \mathrm{H}), 5.63-5.57(\mathrm{~m}, 1 \mathrm{H}), 5.35-5.34(\mathrm{~m}, 1 \mathrm{H})$, 4.99-4.94 (m, 2H), $3.74(\mathrm{~s}, 3 \mathrm{H}), 3.73(\mathrm{~s}, 3 \mathrm{H}), 3.58-3.48(\mathrm{~m}$, $2 \mathrm{H}), 3.25-3.16(\mathrm{~m}, 2 \mathrm{H}), 3.10-3.07(\mathrm{~m}, 1 \mathrm{H}), 2.85-2.75(\mathrm{~m}, 1 \mathrm{H})$, 2.14-2.07 (m, 2H), $2.04(\mathrm{~s}, 3 \mathrm{H}), 2.02-1.85(\mathrm{~m}, 2 \mathrm{H}), 1.69-1.59$ $(\mathrm{m}, 4 \mathrm{H}), 1.53-1.25(\mathrm{~m}, 3 \mathrm{H}), 0.94(\mathrm{~s}, 9 \mathrm{H}), 0.02(\mathrm{~s}, 3 \mathrm{H}),-0.03(\mathrm{~s}$, $3 \mathrm{H}) ;{ }^{13} \mathrm{C}$ NMR $(75 \mathrm{MHz}) \delta 170.1,169.3,168.7,139.5,136.9$, 134.0, 132.5, 115.9, 115.0, 73.4, 65.1, 60.6, 57.6, 56.2, 53.1, $52.4,52.1,40.9,37.6,36.2,34.9,34.7,28.2,26.2(\times 3), 22.1$, $21.8,17.9,-5.8,-6.1$; IR: 2950, 1737, 1434, $1249 \mathrm{~cm}^{-1}$; HRMS-ESI $m / z$ : $[\mathrm{M}+\mathrm{Na}]^{+}$calcd for $\mathrm{C}_{31} \mathrm{H}_{46} \mathrm{O}_{7} \mathrm{SiNa} 581.2911$; found, 581.2914 .

Synthesis of the tetracycle 20. The dienyne 18 (100 mg, $0.25 \mathrm{mmol})$ in degassed anhydrous toluene $(7 \mathrm{~mL})$ was treated with Grubbs' catalyst G-II (22 mg, $0.025 \mathrm{mmol})$ at $65{ }^{\circ} \mathrm{C}$ for 
$5 \mathrm{~h}$. On completion of the reaction (TLC), dimethyl acetylenedicarboxylate $(0.06 \mathrm{~mL}, 0.37 \mathrm{mmol})$ was added to the resulting reaction mixture. The mixture was heated at $65^{\circ} \mathrm{C}$ for $8 \mathrm{~h}$. Removal of the solvent under vacuo followed by column chromatography (15\% EA/PE) afforded the Diels-Alder adduct 20 $(102 \mathrm{mg}, 76 \%)$ as a colorless oil; ${ }^{1} \mathrm{H}$ NMR $(300 \mathrm{MHz})$

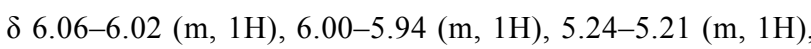
$5.03-4.95(\mathrm{~m}, 2 \mathrm{H}), 3.80(\mathrm{~s}, 3 \mathrm{H}), 3.75(\mathrm{~s}, 3 \mathrm{H}), 3.53(\mathrm{~s}, 2 \mathrm{H})$, 3.19-3.11 (m, 1H), 3.09-3.02 (m, 1H), 3.00-2.86 (m, 1H), 2.43-2.34 (m, 1H), 2.14 (s, 3H), 2.08-1.98 (m, 2H), 1.96-1.78 $(\mathrm{m}, 2 \mathrm{H}), 1.55-1.50(\mathrm{~m}, 2 \mathrm{H}), 1.46-1.41(\mathrm{~m}, 1 \mathrm{H}), 1.34-1.25(\mathrm{~m}$, $1 \mathrm{H}), 1.12-0.99$ (m, 1H), 0.91 (s, 9H), 0.04 (s, 3H), 0.02 (s, 3H); ${ }^{13} \mathrm{C}$ NMR $(75 \mathrm{MHz}) \delta 170.0,169.0,167.5,140.1,139.3,139.2$, $129.0,115.3,109.8,74.4,65.6,62.3,58.1,56.7,54.7,52.4$, $52.3,41.9,40.1,35.9,35.6,27.6,26.2(\times 3), 22.9,21.1,18.2$, $-5.8,-5.9$; IR: 2950, 1731, 1434, $1257 \mathrm{~cm}^{-1}$; HRMS-ESI $m / z:[\mathrm{M}+\mathrm{Na}]^{+}$calcd for $\mathrm{C}_{30} \mathrm{H}_{44} \mathrm{O}_{7} \mathrm{SiNa}$ 567.2754; found, 567.2756 .

\section{Supporting Information}

\section{Supporting Information File 1 \\ Experimental and analytical data. \\ [https://www.beilstein-journals.org/bjoc/content/ supplementary/1860-5397-14-248-S1.pdf]}

\section{Supporting Information File 2}

Crystallographic information for compound $\mathbf{1 3}$.

[https://www.beilstein-journals.org/bjoc/content/ supplementary/1860-5397-14-248-S2.cif]

\section{Acknowledgements}

SG is grateful to Indian National Science Academy, New Delhi for financial support through INSA Senior Scientist program. We are grateful to DST, Government of India for financial support for National Single Crystal Diffractometer facility at the Department of Inorganic Chemistry of this institute. We sincerely thank Mr. Mukesh Choudhary of Institute of Chemical Technology, Mumbai for carrying out some preliminary experiments.

\section{ORCID ${ }^{\circledR}$ iDs}

Subrata Ghosh - https://orcid.org/0000-0003-4564-4435

\section{References}

1. Arjona, O.; Csáky, A. G.; Plumet, J. Eur. J. Org. Chem. 2003, 611-622. doi:10.1002/ejoc.200390100

2. Holub, N.; Blechert, S. Chem. - Asian J. 2007, 2, 1064-1082. doi:10.1002/asia.200700072
3. Bose, S.; Ghosh, S. Proc. Indian Natl. Sci. Acad. 2014, 80, 37-54. doi:10.16943/ptinsa/2014/v80i1/55085

4. Kotha, S.; Meshram, M.; Khedkar, P.; Banerjee, S.; Deodhar, D. Beilstein J. Org. Chem. 2015, 11, 1833-1864. doi:10.3762/bjoc.11.199

5. Stille, J. R.; Santarsiero, B. D.; Grubbs, R. H. J. Org. Chem. 1990, 55, 843-862. doi:10.1021/jo00290a013

6. Zuercher, W. J.; Hashimoto, M.; Grubbs, R. H. J. Am. Chem. Soc. 1996, 118, 6634-6640. doi:10.1021/ja9606743

7. Stragies, R.; Blechert, S. Synlett 1998, 169-170. doi:10.1055/s-1998-1592

8. Arjona, O.; Csákÿ, A. G.; Murcia, M. C.; Plumet, J. Tetrahedron Lett. 2000, 41, 9777-9779. doi:10.1016/S0040-4039(00)01721-4

9. Weatherhead, G. S.; Ford, J. G.; Alexanian, E. J.; Schrock, R. R.; Hoveyda, A. H. J. Am. Chem. Soc. 2000, 122, 1828-1829. doi:10.1021/ja993681a

10. Arjona, O.; Csákÿ, A. G.; Medel, R.; Plumet, J. J. Org. Chem. 2002, 67, 1380-1383. doi:10.1021/jo016000e

11. Sakurai, H.; Daiko, T.; Hirao, T. Science 2003, 301, 1878. doi:10.1126/science.1088290

12. Arjona, O.; Csákÿ, A. G.; León, V.; Medel, R.; Plumet, J. Tetrahedron Lett. 2004, 45, 565-567. doi:10.1016/j.tetlet.2003.10.197

13. Holtsclaw, J.; Koreeda, M. Org. Lett. 2004, 6, 3719-3722. doi:10.1021/ol048650l

14. Funel, J.-A.; Prunet, J. Synlett 2005, 235-238. doi:10.1055/s-2004-837200

15. Chandler, C. L.; Phillips, A. J. Org. Lett. 2005, 7, 3493-3495. doi:10.1021/ol051199t

16. Maechling, S.; Norman, S. E.; Mckendrick, J. E.; Basra, S.; Köppner, K.; Blechert, S. Tetrahedron Lett. 2006, 47, 189-192. doi:10.1016/j.tetlet.2005.10.155

17. Hart, A. C.; Phillips, A. J. J. Am. Chem. Soc. 2006, 128, 1094-1095. doi:10.1021/ja057899a

18. Phillips, A. J.; Hart, A. C.; Henderson, J. A. Tetrahedron Lett. 2006, 47, 3743-3745. doi:10.1016/j.tetlet.2006.03.124

19. Calvet, G.; Blanchard, N.; Kouklovsky, C. Org. Lett. 2007, 9 , 1485-1488. doi:10.1021/ol0702066

20. Henderson, J. A.; Phillips, A. J. Angew. Chem., Int. Ed. 2008, 47 8499-8501. doi:10.1002/anie.200803593

21. Nguyen, N. N. M.; Leclère, M.; Stogaitis, N.; Fallis, A. G. Org. Lett. 2010, 12, 1684-1687. doi:10.1021/ol100150f

22. Lam, J. K.; Pham, H. V.; Houk, K. N.; Vanderwal, C. D. J. Am. Chem. Soc. 2013, 135, 17585-17594. doi:10.1021/ja409618p

23. Malik, C. K.; Ghosh, S. Org. Lett. 2007, 9, 2537-2540. doi:10.1021/ol070906a

24. Maity, S.; Ghosh, S. Tetrahedron Lett. 2008, 49, 1133-1136. doi:10.1016/j.tetlet.2007.12.064

25. Mondal, S.; Malik, C. K.; Ghosh, S. Tetrahedron Lett. 2008, 49, 5649-5651. doi:10.1016/j.tetlet.2008.07.083

26. Malik, C. K.; Yadav, R. N.; Drew, M. G. B.; Ghosh, S. J. Org. Chem. 2009, 74, 1957-1963. doi:10.1021/jo802077t

27. Malik, C. K.; Hossain, M. F.; Ghosh, S. Tetrahedron Lett. 2009, 50, 3063-3066. doi:10.1016/j.tetlet.2009.04.033

28. Mondal, S.; Yadav, R. N.; Ghosh, S. Tetrahedron Lett. 2009, 50, 5277-5279. doi:10.1016/j.tetlet.2009.07.012

29. Maity, S.; Ghosh, S. Tetrahedron 2009, 65, 9202-9210. doi:10.1016/j.tet.2009.09.029

30. Matcha, K.; Maity, S.; Malik, C. K.; Ghosh, S. Tetrahedron Lett. 2010, 51, 2754-2757. doi:10.1016/j.tetlet.2010.03.074

31. Yadav, R. N.; Mondal, S.; Ghosh, S. Tetrahedron Lett. 2011, 52, 1942-1945. doi:10.1016/j.tetlet.2011.02.054 
32. Bose, S.; Ghosh, M.; Ghosh, S. J. Org. Chem. 2012, 77, 6345-6350. doi:10.1021/jo300945b

33. Datta, R.; Bose, S.; Viththlbhai, P. B.; Ghosh, S. Tetrahedron Lett. 2014, 55, 3538-3540. doi:10.1016/j.tetlet.2014.04.091

34. Villar, H.; Frings, M.; Bolm, C. Chem. Soc. Rev. 2007, 36, 55-66. doi:10.1039/B508899M

35. Diver, S. T.; Giessert, A. J. Chem. Rev. 2004, 104, 1317-1382. doi:10.1021/cr020009e

36. Mori, M. Adv. Synth. Catal. 2007, 349, 121-135. doi:10.1002/adsc.200600484

37. Mori, M. Materials 2010, 3, 2087-2140. doi:10.3390/ma3032087

38. Banti, D.; North, M. Adv. Synth. Catal. 2002, 344, 694-704.

39. Banti, D.; Groaz, E.; North, M. Tetrahedron 2004, 60, 8043-8052. doi:10.1016/j.tet.2004.06.114

40. Groaz, E.; Banti, D.; North, M. Eur. J. Org. Chem. 2007, 3727-3745. doi:10.1002/ejoc.200700291

41. Kotha, S.; Ravikumar, O. Tetrahedron Lett. 2014, 55, 5781-5784. doi:10.1016/j.tetlet.2014.08.108

42. Kotha, S.; Ravikumar, O. Eur. J. Org. Chem. 2014, 5582-5590. doi:10.1002/ejoc.201402273

43. Spandl, R. J.; Rudyk, H.; Spring, D. R. Chem. Commun. 2008, 3001-3003. doi:10.1039/B807278G

44. Breitler, S.; Han, Y.; Corey, E. J. Org. Lett. 2017, 19, 6686-6687. doi:10.1021/acs.orglett.7b03412

45. Wright, J.; Drtina, G. J.; Roberts, R. A.; Paquette, L. A. J. Am. Chem. Soc. 1988, 110, 5806-5817. doi:10.1021/ja00225a036

46. Wender, P. A.; Singh, S. K. Tetrahedron Lett. 1990, 31, 2517-2520. doi:10.1016/0040-4039(90)80114-2

47. Hudlicky, T.; Fleming, A.; Radesca, L. J. Am. Chem. Soc. 1989, 111, 6691-6707. doi:10.1021/ja00199a032

48. CCDC 1847091 contains supplementary crystallographic data for the compound 13. These data can be obtained free of charge from The Cambridge Crystallographic Data Centre via http://www.ccdc.cam.ac.uk/data_request/cif.

49. Datta, R.; Ghosh, S. J. Org. Chem. 2017, 82, 7675-7682. doi:10.1021/acs.joc.7b01179

\section{License and Terms}

This is an Open Access article under the terms of the Creative Commons Attribution License (http://creativecommons.org/licenses/by/4.0). Please note that the reuse, redistribution and reproduction in particular requires that the authors and source are credited.

The license is subject to the Beilstein Journal of Organic Chemistry terms and conditions: (https://www.beilstein-journals.org/bjoc)

The definitive version of this article is the electronic one which can be found at: $\underline{\text { doi:10.3762/bjoc. } 14.248}$ 